\title{
Percutaneous Nephrolithotomy in Obese Patients, Is There Any Challenge?
}

\author{
Aso Omer Rashid ${ }^{1,2}$, Mahmmod Mohammed Yahyaa ${ }^{1,2}$ \\ ${ }^{1}$ Department of Surgery, School of Medicine, University of Sulaimani, Sulaimani, Iraq \\ ${ }^{2}$ Department of Urology, Sulaimani Teaching Hospital, Sulaimani, Iraq \\ Email: mahmoodalhayaly@yahoo.com
}

How to cite this paper: Rashid, A.O. and Yahya, M.M. (2018) Percutaneous Nephrolithotomy in Obese Patients, Is There Any Challenge? Open Journal of Urology, 8, 49-58.

https://doi.org/10.4236/oju.2018.82006

Received: October 13, 2017

Accepted: February 25, 2018

Published: February 28, 2018

Copyright (c) 2018 by author and Scientific Research Publishing Inc. This work is licensed under the Creative Commons Attribution International License (CC BY 4.0).

http://creativecommons.org/licenses/by/4.0/

(c) (i) Open Access

\begin{abstract}
Percutaneous nephrolithotomy (PNL) is a safe and effective procedure in the treatment of large renal stones in obese and non-obese patients with low rate of morbidity and high success rate in different groups of body mass index (BMI), some surgeons believe that morbid obesity increases the risk of complications of PNL, but different recent studies showed there were no significant differences. Objective: To analyze the outcomes of PNL in patients with different BMI and to assess the effects of obesity in the result of PNL in terms of efficacy \& safety regarding total operative time, blood transfusion, organ injury, stone clearance, hospital stay, and the need of auxiliary procedures. Patients and methods: This is a prospective study on patients with different body mass indexes need PNL. Age above 18 years with no co-morbidity had been included in this study from Jan 2015-Oct 2016 in governmental \& two private hospitals in Sulaimania, after application of exclusion and inclusion criteria. All patients had a questioner's paper to agree on participation in this study. Patients were classified into 3 groups according to the World Health Organization (WHO) classification of body mass index (BMI). Standard PNL with ideal instruments had been used. Intra operative and post-operative findings recorded in Excel data sheet. The patients were followed for one month. The outcomes in these 3 groups were compared. Results \& analysis of the data: A total 117 patients had PNL. There was no any statistically significant difference between different BMI groups intra operatively \& post operatively in this study with $(P$ value $<0.05)$ regarding stone clearance, operative time, hospital stay, organ injury, Hemoglobin drop, post-operative renal impairment, and post-operative fever. Conclusion: PNL operation is a relatively safe \& efficacious treatment for patients having renal stone with different BMI range from normal to obese patients without significant challenge.
\end{abstract}


Keywords

PNL, Obese, Stone

\section{Introduction}

Obesity has become a worldwide epidemic, and its prevalence has been projected to grow by $40 \%$ in the next decade. In 2014, over 600 million adults worldwide, 18 years and older, were obese [1]. It has rapidly increased in recent years both in developed and developing countries. The prevalence of overweight and obesity ranged from 25\% to 81.9\% between 1990 and 2011 among adults in the Eastern Mediterranean Region. Among Iranian children and adolescents, the prevalence of obesity ranged from $1 \%$ to $16.1 \%$ between 1990 and 2013 [2]. Because of increased prevalence of sedentary life, decrease in physical activity, obesity has become an important health problem worldwide [3]. Obese patients have a higher incidence of comorbidity [4], this situation has major implications for mortality rates and health care costs [5]. On examination of more than 4500 patients with a history of kidney stones showed that urinary $\mathrm{pH}$ was inversely related to body weight [6]. Larger body size may also result in increased urinary excretion of uric acid and oxalate, risk factors for calcium oxalate kidney stones [7], presumably due to increased endogenous oxalate production. Men, who on average have a larger body size than women, have a life time risk of stone formation three times that of women [8]. According to both EAU \& AUA, the PNL is the first line treatment for renal calculi $\geq 2 \mathrm{~cm}$ [9].

In the morbidly obese, symptomatic renal stones may therefore need to be managed with other treatment methods. For renal pelvicalyceal stones, the choices are between flexible ureteroscopy, percutaneous surgery and open surgery [10].

\section{Patients and Methods}

After obtaining the Iraqi board approval, we evaluate prospectively the PNL operations performed in our centers in Sulaimania governmental hospital \& two private centers between Jan 2015-Oct 2016. After application of exclusion and inclusion criteria to all patients. Patients younger than 18 years of age, renal congenital anomalies, moderate or severe hydronephrosis, sepsis and any associated co morbidity were excluded from the study. A series of pre-operative and post-operative details were recorded in our data base. The 117 patients ( 72 male \& 45 female) were distributed in to three groups using the WHO classification of body mass index. Modified clavien classification was used for reporting the complication, the outcomes of PNL in these 3 groups were compared using collected Excel sheet.

Preoperatively, all patients were informed about treatment alternatives, and they undersigned informed consent forms. History, physical and investigations were done. Preoperatively the patients were assessed for stone size, number, lo- 
cation, anatomy of urinary system, determination of skin to stone distance using computed tomography $(\mathrm{CT})$. Stone surface area was measured by multiplying the longest diameter of the stone by its intersecting vertical diameter as explained in EAU (European Association of Urology) guidelines. After administration of general or spinal anesthesia. An antibiotic given before induction $\left(3^{\text {rd }}\right.$ generation cephalosporin) IV slowly, PNL carried out in prone position. Serial Amplantz facial dilator (Amplatz Renal Dilator Set, Cook Medical, IN, USA) used to create access tract for all patients. Following entrance into pelvicalyceal system with a $26 \mathrm{~F}$ rigid nephroscopy. Long access sheath was used when needed and fixed to the skin edges by nylon sutures. Pneumatic lithotripsy used in stone fragmentation with or without laser (Holmium YAG). A flexible nephroscopy used to visualize the calyxes and fluoroscopy for stone clearance. All patients had JJ stent 4.8 Fr. \& (16 - 24) Fr latex nephrostomy tube. On the first postoperative day, all patients had X-Ray to evaluate their stone-free. Post operatively patients monitored for possible complication \& clavien system used to determine the degree of complication, Patients with no complications discharged the day after operation after nephrostomy \& Foleys catheter removal. Blood was transfused for those who have bleeding. In case of supra-costal puncture, a chest, X-ray was done to exclude pneumothorax. Patients with complications were kept in hospital for follow up till they became well then discharged. All patients rechecked after 4 weeks for stone clearance, hematuria, UTI, JJ stent and any other complications.

After data collection, the questions of study were coded. Data entry performed via using an excel spreadsheet then the statistical analysis was performed by SPSS program, version 21 (IBM SPSS Statistical Package for the Social Sciences).

The data presented in tabular forms showing the frequency and relative frequency distribution of different variables. Chi-square tests were used to compare the categorical data between these three groups of patients in respect to different variables as age groups, gender, presence of hydronephrosis, type of anesthesia, operation time, operation outcomes and follow up of each group post operatively, and the outcome variables. Independent $t$ test was used to compare the quantitative variables among different patient characteristics, paired $t$ test was used to compare pre-and post-operation renal function test among each groups of patients separately. Different types of Bar charts and Pie charts were used to describe some variables of the study diagrammatically. $P$ values of 0.05 were used as a cut off point for significance of statistical tests.

\section{Results}

One hundred seventeen patients with different age \& BMI group were identified, as shown in Figure 1 and Figure 2. For patients, demographic data see Table 1.

Forty (34.2\%) patients with mild hydronephrosis, 77 patients $(65.8 \%)$ without hydronephrosis. 74 patients operated on under GA (63.2\%) \& 43 patients had SA (36.8\%). 104 patients had single puncture (88.9\%), 12 patients had 2 punctures (10.3\%) \& 1 patients had 3 punctures (0.9\%). See Table 2.

Stone clearance intra operatively $99.1 \%$, prolonged bleeding occurred in 5 


\section{Obesity}

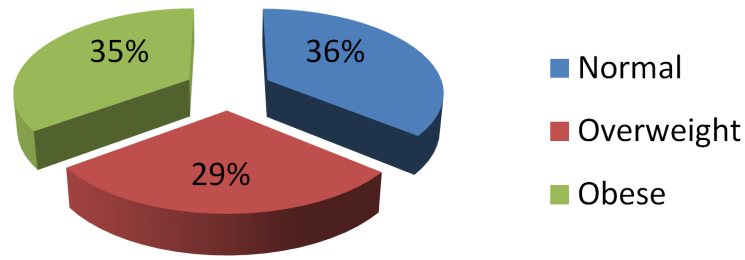

Figure 1. Show BMI distributions.

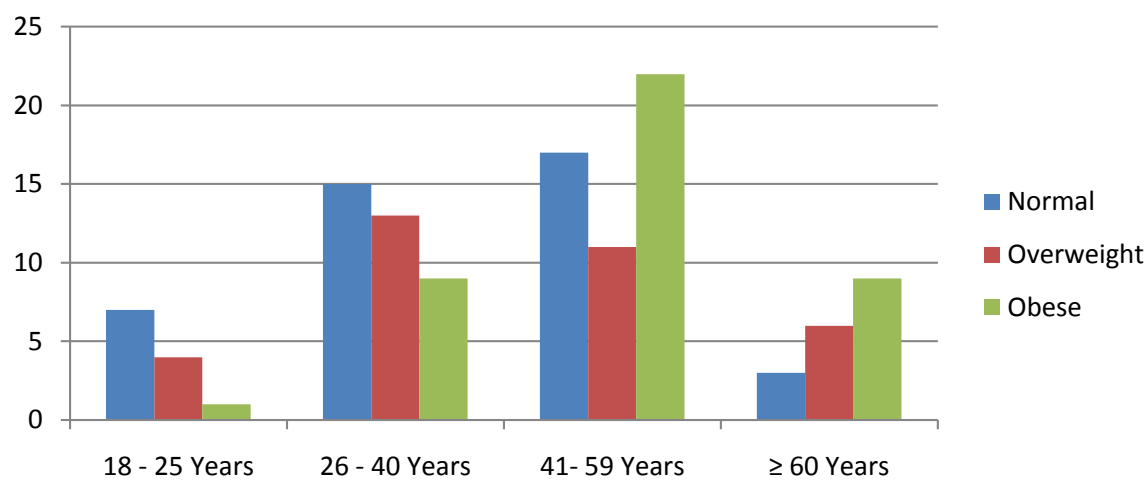

Figure 2. Age distribution in relation to BMI.

Table 1. Demographic distribution of data.

\begin{tabular}{cccc}
\hline & \multicolumn{1}{c}{ Variable } & No. of patients & Percentage \\
\hline \multirow{3}{*}{ Age } & $18-25$ Years & 12 & $10.3 \%$ \\
& $26-40$ Years & 37 & $31.6 \%$ \\
& $41-59$ Years & 50 & $42.7 \%$ \\
Gender & 260 Years & 18 & $15.4 \%$ \\
& Male & 72 & $61.5 \%$ \\
BMI $\left(\mathrm{Kg} / \mathrm{m}^{2}\right)$ & Female & 45 & $38.5 \%$ \\
& Overmal (19 - 24.9) & 42 & $35.9 \%$ \\
& Obese (30 - 34.9) & 34 & $29.1 \%$ \\
& & 41 & $35.0 \%$
\end{tabular}

Table 2. Frequency \& percentage of hydronephrosis, type of anesthesia, number of tracts.

\begin{tabular}{|c|c|c|c|}
\hline \multicolumn{2}{|c|}{ Variable } & \multirow{2}{*}{$\begin{array}{c}\text { Frequency } \\
40\end{array}$} & \multirow{2}{*}{$\begin{array}{c}\text { Percentage } \\
34.2 \%\end{array}$} \\
\hline & Yes & & \\
\hline Hyaronephrosis & No & 77 & $65.8 \%$ \\
\hline \multirow{2}{*}{ Anesthesia } & GA & 74 & $63.2 \%$ \\
\hline & Spinal & 43 & $36.8 \%$ \\
\hline \multirow{3}{*}{ Number of tracts } & 1 & 104 & $88.9 \%$ \\
\hline & 2 & 12 & $10.3 \%$ \\
\hline & 3 & 1 & $0.9 \%$ \\
\hline
\end{tabular}


(4.3\%) of patients, $11(9.4 \%)$ patients had blood transfusion in. $3(2.6 \%)$ patients had pleural injury \& colonic injury occurred in 1 (0.9\%) patient. 19 (16.2\%) patients had post-operative fever. See Table 3.

We distributed patient's variables (age, gender, presence of hydronephrosis, type of anesthesia, presence of blood transfusion, presence of fever, number of tracts) according to BMI groups (normal weight, overweight, obese) patients. See Table 4.

Table 3. The frequency \& percentage of intra operative data.

\begin{tabular}{cccc}
\hline Variable & & Frequency & Percentage \\
\hline Intraoperative & Yes & 116 & $99.1 \%$ \\
stone clearance & No & 1 & $0.9 \%$ \\
Prolonged bleeding & Yes & 5 & $4.3 \%$ \\
& No & 112 & $95.7 \%$ \\
Blood Transfusion & Yes & 11 & $9.4 \%$ \\
& No & 106 & $90.6 \%$ \\
Organ injury & None & 113 & $96.6 \%$ \\
& Pleura & 3 & $2.6 \%$ \\
Fever & Colon & 1 & $0.9 \%$ \\
& Yes & 19 & $16.2 \%$ \\
Stone clearance & No & 98 & $83.8 \%$ \\
(after one month) & Yes & 110 & $94.0 \%$ \\
& No & 7 & $6.0 \%$ \\
\hline
\end{tabular}

Table 4. Distribution of variables according to BMI group \& its $P$ values.

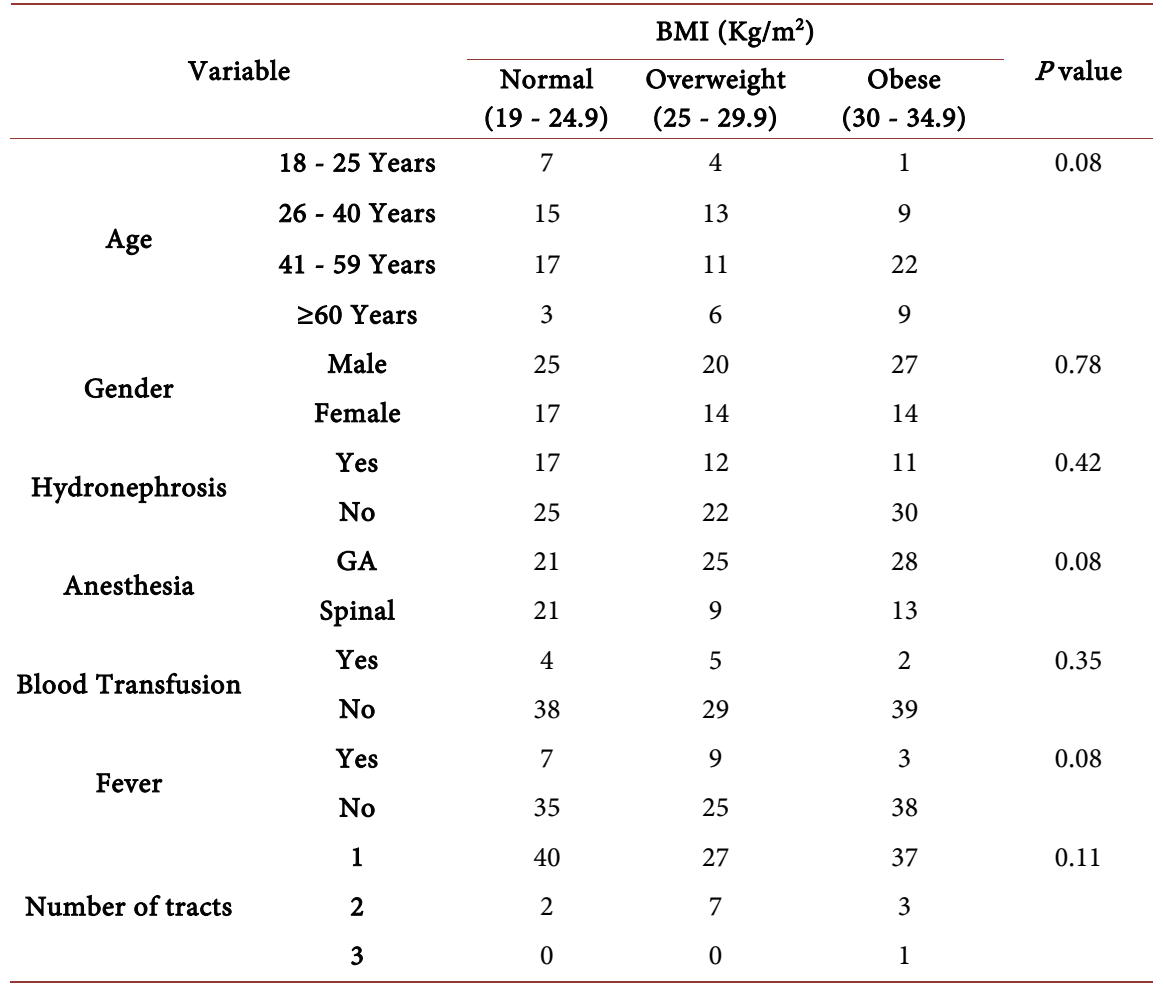


The organ injury, prolonged bleeding, hospital stay \& stone clearance after one month distributed according to BMI groups, there is no statistical difference in hospital stay, prolonged bleeding \& stone clearance for different BMI groups. See Table 5 and Figure 3.

The mean stone size and mean $\mathrm{Hb}$ drop were statistically not significant, see Table 6.

Table 5. Distribution of complications and outcomes according to BMI group \& its $P$ values.

\begin{tabular}{|c|c|c|c|c|c|c|}
\hline \multirow[b]{2}{*}{ Variable } & & \multicolumn{3}{|c|}{$\mathrm{BMI}\left(\mathrm{Kg} / \mathrm{m}^{2}\right)$} & \multirow[b]{2}{*}{ Total } & \multirow[b]{2}{*}{$P$ value } \\
\hline & & $\begin{array}{l}\text { Normal } \\
(19-24.9)\end{array}$ & $\begin{array}{l}\text { Overweight } \\
(25-29.9)\end{array}$ & $\begin{array}{c}\text { Obese } \\
(30-34.9)\end{array}$ & & \\
\hline \multirow{2}{*}{$\begin{array}{l}\text { Stone clearance after one } \\
\text { month }\end{array}$} & Yes & 40 & 31 & 39 & 110 & 0.71 \\
\hline & No & 2 & 3 & 2 & 7 & \\
\hline \multirow{2}{*}{ prolonged bleeding } & Yes & 2 & 1 & 2 & 5 & 0.90 \\
\hline & No & 40 & 33 & 39 & 112 & \\
\hline \multirow{3}{*}{ Organ injury } & None & 39 & 33 & 41 & 113 & 0.44 \\
\hline & Pleura & 2 & 1 & 0 & 3 & \\
\hline & Colon & 1 & 0 & 0 & 1 & \\
\hline
\end{tabular}

Table 6. Distribution of means of stone size \& Hb drop according to BMI groups.

\begin{tabular}{ccccc}
\hline & \multicolumn{3}{c}{ BMI $\left(\mathrm{Kg} / \mathrm{m}^{2}\right)$} & \\
\cline { 2 - 4 } Variable & $\begin{array}{c}\text { Normal } \\
(19-24.9)\end{array}$ & $\begin{array}{c}\text { Overweight } \\
(25-29.9)\end{array}$ & $\begin{array}{c}\text { Obese } \\
(30-34.9)\end{array}$ & Pvalue \\
\hline Stone size $\left(\mathrm{cm}^{2}\right)$ & $28.43 \pm 5.83$ & $31.79 \pm 6.50$ & $30.66 \pm 6.89$ & 0.07 \\
Hb drop $(\mathrm{gm} / \mathrm{dl})$ & $0.84 \pm 0.25$ & $0.91 \pm 0.23$ & $0.90 \pm 0.24$ & 0.40 \\
\hline
\end{tabular}

Stone clearance after one month

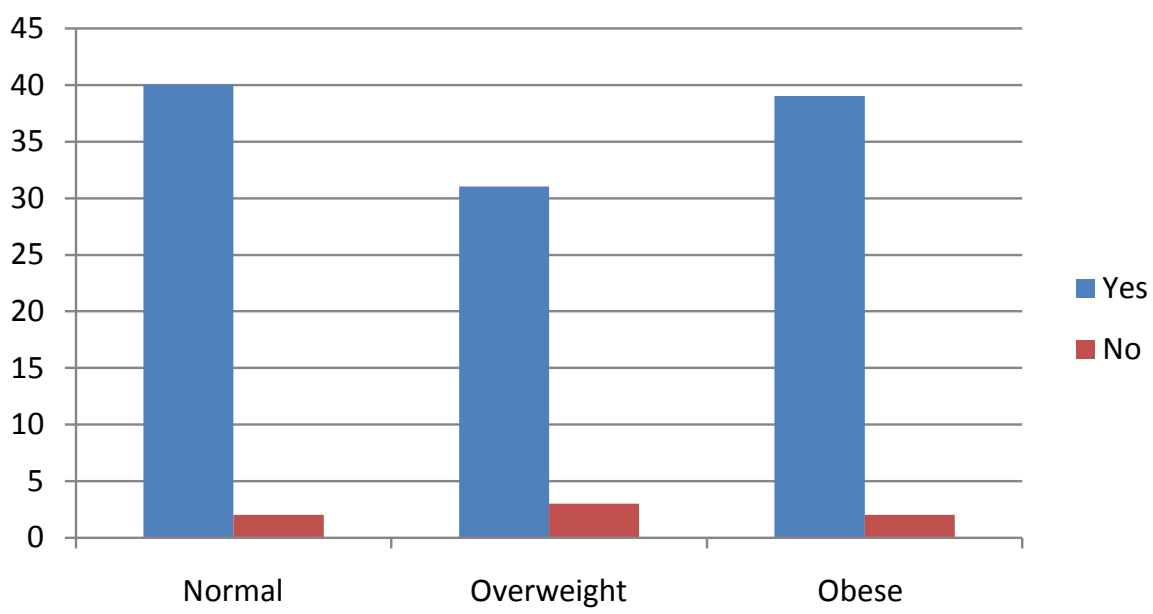

Figure 3. Show stone clearance after one month according to their BMI. 
The following Table 7 show no statistical difference for mean blood urea \& mean serum creatinine in different BMI groups pre-operatively \& post operatively.

There was no statistically significant difference between mean duration of operation \& mean hospital stay in different BMI groups. See Table 8 and Figure 4.

Table 7. Preoperative \& postoperative mean blood urea \& mean serum creatinine of patients according BMI groups.

\begin{tabular}{|c|c|c|c|c|}
\hline \multirow{2}{*}{\multicolumn{2}{|c|}{$\begin{array}{l}\text { Pre-and Post Op renal function } \\
\text { BMI }\left(\mathrm{Kg} / \mathrm{m}^{2}\right)\end{array}$}} & \multicolumn{2}{|c|}{ Mean $\pm S D$} & \multirow{2}{*}{$P$ Value } \\
\hline & & Pre-operative & Post-operative & \\
\hline \multirow{3}{*}{ Blood Urea } & $\begin{array}{l}\text { Normal } \\
(19-24.9)\end{array}$ & $29.86 \pm 5.96$ & $29.86 \pm 6.17$ & 0.5 \\
\hline & $\begin{array}{c}\text { Overweight } \\
(25-29.9)\end{array}$ & $31.1 \pm 9.2$ & $29.4 \pm 5.8$ & 0.09 \\
\hline & $\begin{array}{c}\text { Obese } \\
(30-34.9)\end{array}$ & $32.9 \pm 5.5$ & $32.8 \pm 5.5$ & 0.46 \\
\hline \multirow{3}{*}{ Serum creatinine } & $\begin{array}{l}\text { Normal } \\
(19-24.9)\end{array}$ & $0.94 \pm 0.16$ & $0.96 \pm 0.15$ & 0.24 \\
\hline & $\begin{array}{c}\text { Overweight } \\
(25-29.9)\end{array}$ & $0.90 \pm 0.16$ & $0.94 \pm 0.16$ & 0.15 \\
\hline & $\begin{array}{c}\text { Obese } \\
(30-34.9)\end{array}$ & $0.94 \pm 0.15$ & $0.96 \pm 0.16$ & 0.26 \\
\hline
\end{tabular}

Table 8. Mean operative time \& hospital stay according BMI groups.

\begin{tabular}{ccccc}
\hline & \multicolumn{3}{c}{ BMI $\left(\mathrm{Kg} / \mathrm{m}^{2}\right)$} \\
\cline { 2 - 4 } Variable & $\begin{array}{c}\text { Normal } \\
(19-24.9)\end{array}$ & $\begin{array}{c}\text { Overweight } \\
(25-29.9)\end{array}$ & $\begin{array}{c}\text { Obese } \\
(30-34.9)\end{array}$ & Pvalue \\
\cline { 2 - 4 } & \multicolumn{3}{c}{ Mean \pm SD } \\
Duration of Operation (Minutes) & $48.1 \pm 7.4$ & $51.6 \pm 9.2$ & $51.7 \pm 10.0$ & 0.12 \\
Hospital Stay (Days) & $1.24 \pm 0.48$ & $1.29 \pm 0.46$ & $1.15 \pm 0.42$ & 0.37 \\
\hline
\end{tabular}

Hospital stay versus Obesity

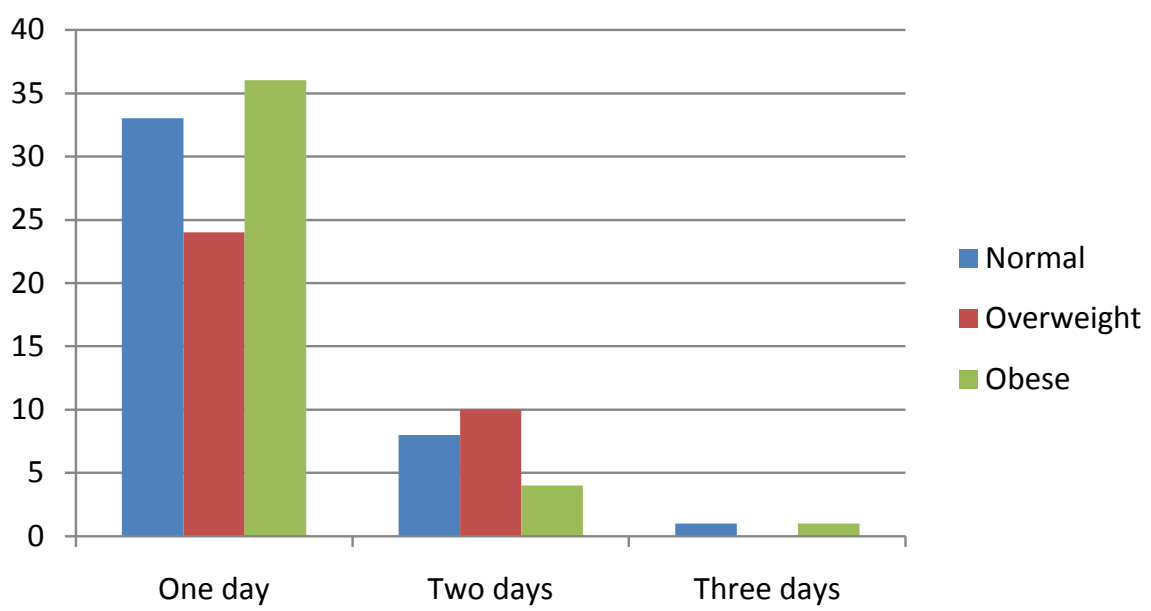

Figure 4. Show hospital stay in different BMI groups. 


\section{Discussion}

Percutaneous nephrolitholapaxy (PNL) has been an essential technique for 35 years for kidney stone removal, avoiding complications of open surgery [11].

To determine the effect of BMI alone on the surgery in patients free from co-morbidity. Our patients were stratified into 3 different groups according to their BMI and we found the most affected age groups of obese patients were age group (41 - 59) years $42.7 \%$. With a male/female ratio $1.59: 1$. The males $61.5 \%$ more affected than females $38.5 \%$. In our study the average stone size with $P$ value 0.42 and the types of anesthesia administration with $P$ value 0.08 were statistically not significant.

In 117 patients; 104 (88.9\%) patients had single tract, 12 (10.3\%) patients had 2 punctures due to either big stone size or difficult negotiation of calyx , $1(0.9 \%)$ patient need 3, no any statistically significant difference found between different BMI groups of patients in number of tracts needed to complete the PNL ( $P$ value $=0.11$ ). The complex stone rather than obesity which affect the number of tracts needed, Aron et al. presented data to support multitract PNL for large staghorn calculi he concluded that PNL monotherapy using multiple tracts is safe and effective, and should be the first option for massive renal staghorn calculi [12].

Our study shows mean operative time indifference BMI was statistically not significant $(P$ value $=0.12$ ).

Labate et al. found longer operative time of PNL in obese patients [13]. Pearle et al. showed that in 57 patients with a BMI of $>30 \mathrm{~kg} / \mathrm{m}^{2}$ the operative time was slightly longer but outcomes in terms of stone-free and complication rates were not different compared to 179 patients with a BMI of $<30 \mathrm{~kg} / \mathrm{m}^{2}$ [14].

One of the most important complication in PNL is blood loss, in our study (9.4\%) 11 patients had blood transfusion: 4, 5 and 2 for normal weight, overweight, and obese patients respectively which was statistically not significant $(P$ value $=0.35)$. Prolonged bleeding post operatively occurred in 5 patients; 2,1 and 2 patients in normal weight, over weight and obese patients respectively which is statistically not significant $(P$ value $=0.90)$. The $\mathrm{Hb}$ drop between different BMI groups which was statistically not significant $(P$ value $=0.4)$.

Ortiz et al. prospectively evaluated 255 patients had PNL; they found no difference in $\mathrm{Hb}$ drop, blood transfusion rate in different BMI groups [15].

Colonic injury occurred in 1 patient $0.9 \%$ and pleural injury occurred in 3 patients $2.6 \%$. Which was statistically not significant $(P$ value $=0.44)$. Taylor et al. found injury to colon range $0.2 \%$ to $1 \%$ and pleural injury $0.3 \%$ to $1 \%$ in patients had PNL [16].

Post-operative renal function was compared to pre-operative renal function for different BMI groups, which was statistically not significant that clarified safety of PNL in different BMI groups. Taylor et al. found $1 \%$ transient increase in serum creatinine post PNL which is not clinically significant [16].

Post-operative fever (clavien II) occurred in 19 (16.2\%) patients. There was no statistically significant difference between BMI groups $(P$ value $=0.08)$. Ortiz et 
al., Shahab et al. found no effect of BMI on post-operative fever [17] [18]. Aso Omer et al. describe fever after PNL in $28.3 \%$ in which 7 patients were obese and $5 \%$ had sepsis, the BMI was not a significant factor [19].

Mean hospital stay for patients were $1.24 \pm 0.48,1.29 \pm 0.46,1.15 \pm 0.42$ days for normal weight, overweight and obese patients group with $(P=0.37)$ which is statistically not significant. That mean obesity doesn't prolong hospital stay in PNL surgery, Taylor et al. found longer hospital stay in obese patients although Shohab et al. found no effect of BMI on hospital stay while Trudeu et al. found prolong hospital stay [16] [18] [20].

After one month, all patients were seen for stone clearance, stone free rate was $94 \%$, residual stone rate $6 \%$. Shohab et al. analyzed 129 patients with three BMI group underwent PNL retrospectively and found no effect of BMI on stone clearance although Ortiz et al., Taylor et al. found low stone clearance rate in obese patients [15] [16] [18].

Multiple regression analysis revealed that increasing BMI do influence the operative risk of bleeding, transfusion, leak, intensive care unit admission, sepsis and inversely influence the stone-free rate. They conclude that Obese patients have higher operative complication risk and low stone-free rate on PCNL [21].

\section{Conclusion}

PNL operation is a safe \& efficacious treatment for patients without co-morbidities having renal stone with different BMI range from normal to obese patients regarding operative time, bleeding, post-operative fever, organ injury, stone clearance $\&$ hospital stay.

\section{References}

[1] Kovesdy, C.P., Furth, S.L. and Zoccali, C. (2017) Obesity and Kidney Disease: Hidden Consequences of the Epidemic. Blood Purification, 43, 346-354. https://doi.org/10.1159/000458481

[2] Zhou, X.J., Sun, X.B., Chen, X.H., Gong, X.X., Yang, Y., Chen, C.B. and Yao, Q.S. (2017) Effect of Obesity on Outcomes of Percutaneous Nephrolithotomy in Renal Stone Management: A Systematic Review and Meta-Analysis. Urologia Internationalis, 98, 382-390. https://doi.org/10.1159/000455162

[3] O’Brien, P.E. and Dixon, J.B. (2002) The Extent of the Problem of Obesity. American Journal of Surgery, 184, 4S-8S. https://doi.org/10.1016/S0002-9610(02)01172-8

[4] Michel, M.S., Trojan, L. and Rassweiler, J.J. (2007) Complications in Percutaneous Nephrolithotomy. European Urology, 51, 899-906. https://doi.org/10.1016/j.eururo.2006.10.020

[5] Şimşek, A., Özgör, F., Akbulut, M.F., Küçüktopçu, O., Oğlu, A.Y.B., Sarılar, Ö., Binbay, M. and Anoğlu, A.Y.M. (2014) Does Body Mass Index Effect the Success of Percutaneous Nephrolithotomy? Turkish Journal of Urology, 40, 104-109.

[6] Taylor, E.N., Stampfer, M.J. and Curhan, G.C. (2005) Obesity, Weight Gain, and the Risk of Kidney Stones. JAMA, 293, 455-462. https://doi.org/10.1001/jama.293.4.455

[7] Asplin, J.R. (2009) Obesity and Urolithiasis. Advance Chronic Kidney Disease, 16, 11-20. https://doi.org/10.1053/j.ackd.2008.10.003 
[8] Curhan, G.C., Willett, W.C., Rimm, E.B., Speizer, F.E. and Stampfer, M.J. (1998) Body Size and Risk of Kidney Stones. Journal of the American Society of Nephrolo$g y$, 9, 1645-1652.

[9] Keheila, M., Leavitt, D., Galli, R., Motamedinia, P., Theckumparampil, N., Siev, M., Hoenig, D., Smith, A. and Okeke, Z. (2016) Percutaneous Nephrolithotomy in Super Obese Patients (Body Mass Index $\geq 50 \mathrm{~kg} / \mathrm{m} 2$ ): Overcoming the Challenges. BJU International, 117, 300-306. https://doi.org/10.1111/bju.13155

[10] Koo, B.C., Burtt, G. and Burgess, N.A. (2004) Percutaneous Stone Surgery in the Obese: Outcome Stratified According to Body Mass Index. BJU International, 93, 1296-1299. https://doi.org/10.1111/j.1464-410X.2004.04862.x

[11] Al-Kohlany, K.M., Shokeir, A.A., Mosbah, A., et al. (2005) Treatment of Complete Staghorn Stones: A Prospective Randomized Comparison of Open Surgery versus Percutaneous Nephrolithotomy. Journal of Urology, 173, 469-473. https://doi.org/10.1097/01.ju.0000150519.49495.88

[12] Aron, M., Yadav, R., Goel, R., et al. (2005) Multi-Tract Percutaneous Nephrolithotomy for Large Complete Staghorn Calculi. Urologia Internationalis, 75, 327-332. https://doi.org/10.1159/000089168

[13] Labate, G., Modi, P., Timoney, A., Cormio, L., Zhang, X., Louie, M., Grabe, M. and de la Rosette, J. (2011) The Percutaneous Nephrolithotomy Global Study: Classification of Complications. Journal of Endourology, 25, 1275-1280.

[14] Pearle, M.S., Nakada, S.Y., Womack, J.S. and Kryger, J.V. (1998) Outcomes of Contemporary Percutaneous Nephrostolithotomy in Morbidly Obese Patients. Journal of Urology, 160, 669-673. https://doi.org/10.1016/S0022-5347(01)62750-2

[15] Torrecilla Ortiz, C., Meza Martínez, A.I., Vicens Morton, A.J., Vila Reyes, H., Colom Feixas, S., Suarez Novo, J.F. and Franco Miranda, E. (2014) Obesity in Percutaneous Nephrolithotomy, Is Body Mass Index Important? Urology, 84, 538-543. https://doi.org/10.1016/j.urology.2014.03.062

[16] Taylor, E., Miller, J., Chi, T. and Stoller, M.L. (2012) Complications Associated with Percutaneous Nephrolithotomy. Translational Andrology and Urology, 1, 223-228.

[17] De la Rosette, J., Assimos, D., Desai, M., et al. (2011) The Clinical Research Office of the Endourological Society Percutaneous Nephrolithotomy Global Study: Indications, Complications, and Outcomes in 5803 Patients. Journal of Endourology, 25, 11-17. https://doi.org/10.1089/end.2010.0424

[18] Shohab, D., Ayub, R., Alam, M.U., Butt, A., Sheikh, S., Assad, S. and Akhter, S. (2015) Effect of Body Mass Index on Operative Time, Hospital Stay, Stone Clearance, Postoperative Complications, and Postoperative Analgesic Requirement in Patients Undergoing Percutaneous Nephrolithotomy. Turkish Journal of Urology, 41, 177-180. https://doi.org/10.5152/tud.2015.61482

[19] Rashid, A.O. and Fakhulddin, S.S. (2016) Risk Factors for Fever and Sepsis after Percutaneous Nephrolithotomy. Asian Journal of Urology, 3, 82-87.

[20] Trudeau, V., Karakiewicz, P.I., Boehm, K., Dell'Oglio, P., Tian, Z., Briganti, A., Shariat, S.F., Valiquette, L. and Bhojani, N. (2016) The Effect of Obesity on Perioperative Outcomes Following Percutaneous Nephrolithotomy. Journal of Endourology, 30, 864-870.

[21] Banakhar, M.A., Al-Sayyad, A.J., Altayib, A. and Mosli, H.A. (2011) The Effect of Body Mass Index on Stone-Free Rate and Operative Complication Rate of Percutaneous Nephrolithotomy. Current Urology, 5, 18-22.

https://doi.org/10.1159/000327443 